\title{
ІНФОРМАЦІЙНО-ТЕХНОЛОГІЧНІ ПРОБЛЕМИ ОРГАНІЗАЦІЇ ТЕЛЕМЕДИЧНИХ КОНСУЛЬТАЦІЙ
}

\author{
О. П. Мінцер, В. В. Краснов, Г. Тахере \\ Національна медична академія післядипломної освіти імені П. Л. Шупика
}

\begin{abstract}
Розглянуті шляхи формалізації лікувально-діагностичного процесу для зменшення кількості можливих помилок, що пов'язані з недостатнім обстеженням хворого, викривленнями діагностичних відомостей, помилковою інтерпретацією отриманої інформації.
\end{abstract}

Ключові слова: телемедицина, інформаційні технології, формалізація та стандартизація технологічних процедур, автоматні моделі лікувального процесу.

\section{ИНФОРМАЦИОННО-ТЕХНОЛОГИЧЕСКИЕ ПРОБЛЕМЫ ОРГАНИЗАЦИИ ТЕЛЕМЕДИЦИНСКИХ КОНСУЛЬТАЦИЙ}

\author{
О. П. Минцер, В. В. Краснов, Г. Тахере \\ Национальная медицинская академия последипломного образования имени П.Л. Шупика

\begin{abstract}
Рассмотрены пути формализации лечебно-диагностического процесса для уменьшения количества возможных
\end{abstract} \\ ошибок, связанных с недостаточным обследованием больного, искривлениями диагностических сведений, оши- \\ бочной интерпретацией полученной информации.
}

Ключевые слова: телемедицина, информационные технологии, формализация и стандартизация технологических процедур, автоматные модели лечебного процесса.

\section{INFORMATIVELY-TECHNOLOGICAL PROBLEMS OF ORGANIZATION OF TELEMEDICAL CONSULTATIONS}

\author{
O. P. Mintser, V. V. Krasnov, H. Takhere \\ National Medical Academy of Post-Graduate Education named after P. L. Shupyk
}

\begin{abstract}
The ways of formalization of curatively-diagnostic process are considered for diminishing of amount of the possible errors, related to the insufficient inspection of the patient, curvatures of diagnostic information, erroneous interpretation of the received information.
\end{abstract}

Key words: telemedicine, information technologies, formalization and standardization of technological procedures, automatic models of curative process.

Вступ. Відомо, що головним завданням телемедичних консультацій (ТK) $є\left(L^{q}\right)$ здійснення певних лікувальних впливів (у більшості стандартизованих) для переводу пацієнта зі стану, що відповідає незадовільному стану на вході в процес (тобто $W\left(p^{i n}\right)=$ $W\left(\tilde{p}^{i n}{ }_{i}\right)$, де $p^{i n}{ }_{i}=\left\{\tilde{\gamma}^{i n}{ }_{i_{1}}, \tilde{\gamma}^{i n}{ }_{i_{2}}, \ldots, \tilde{\gamma}^{i n}{ }_{i_{k}}\right\} \mathrm{i} \operatorname{val}\left(\gamma^{i n}{ }_{i_{s}}\right)$ $\left.=\alpha^{i n}{ }_{i_{s}} \in\left[a^{i n}{ }_{i}, b^{i n}{ }_{i}\right]\right)$, у стан, що також відповідає більш позитивному стану на виході з клінічного процесу (КП) (тобто $W\left(p^{\text {out }}\right)=W\left(\tilde{p}_{i}^{\text {out }}{ }_{i}\right)$, де $p^{\text {out }}{ }_{i}=$ $\left\{\tilde{\gamma}^{\text {out }}{ }_{i_{1}}, \tilde{\gamma}^{\text {out }}{ }_{i_{2}}, \ldots, \tilde{\gamma}^{\text {out }}{ }_{i_{k}}\right\}$ i $\operatorname{val}\left(\gamma^{\text {out }}{ }_{i_{s}}\right)=\alpha^{\text {out }}{ }_{i_{s}} \in$ $\left.\left[a^{\text {out }}{ }_{i}, b^{\text {out }}{ }_{i}\right]\right)$.

Зрозуміло, що виходом з лікувального процесу може бути ситуація, коли параметри стану пацієнта відхилилися за межі відповідних критичних. У такому разі стан об'єкта вважається вже таким, що не належить простору ознак $W\left(\widetilde{p}^{\text {out }}{ }_{i}\right)$ і об'єкт повертається на початковий рівень діагностичного процесу (рис. 1).

Вочевидь, діагностична та лікувальна процедури при телемедичній консультації можуть бути строго детерміновані.

Метою дослідження було визначення складових діагностичного та лікувального процесів (ДП і ЛП) під час телемедичного консультування, розроблення їх формального опису; визначення формату опису ДП 
Телемедичні консультації

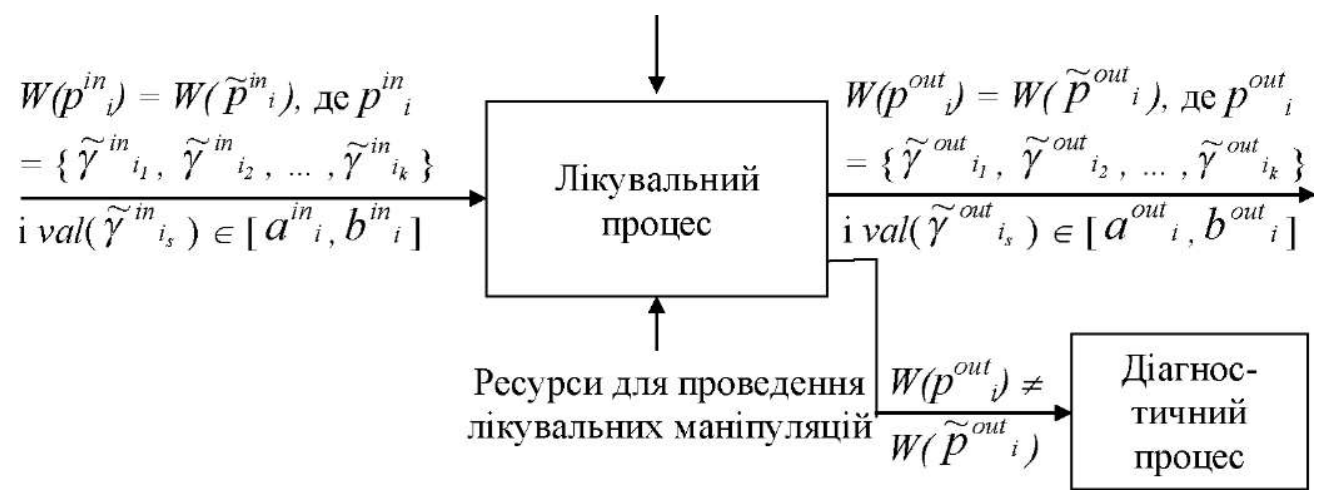

Puc. 1. Схема лікувального процесу.

і ЛП для максимально точного відображення при передаванні інформації.

Результати та їх обговорення. Аналізуючи лікарську логіку під час побудови діагнозу та вибору методу лікування припустили, що діяльність медичного працівника в стандартних ситуаціях моделюється за допомогою кінцевого автомату (рис. 1).

Переваги автоматних моделей перед іншими моделями опису предметних областей полягають у наступному [1]:

1. Основа автоматної моделі - гарна алгоритмічна база, що не вимагає синхронізації (всі основні завдання алгоритмічно розв'язні).

2. Всі процеси, що описані в автоматній моделі кінцеві.

Тому вважаємо доцільним при організації телемедичного консультування визначити стандартні складові діагностичного процесу, розробити його формальний опис і модель у вигляді кінцевого автомату.

Відповідно до основ побудови автоматних моделей, на вхід у систему подається сигнал, далі він обробляється за заздалегідь визначеними алгоритмами, на виході отримуємо очікуваний набір значень. В автоматній моделі також враховується факт появи в реальній ситуації фактора, що виводить реальну ситуацію за межі стандартної, то подібна ситуація ідентифікується та подається для вирішення на експертний рівень.

Автомат можна описати таким чином:

$A=\left(\mathrm{A}, \mathrm{X}, f, a_{0}, \mathrm{~F}\right)$, де

$A$ - кінцева множина станів;

$\mathrm{X}$ - кінцевий алфавіт, тобто множина попарно різних символів або $X$ - сигнал (команда) до переходу;

$f$ - взаємозв'язок послідовності станів через переходи, тобто функція переходів;

$a_{0}$ - початковий стан автомата;

$\mathrm{F} \subseteq \mathrm{A}$ - множина заключних станів автомата.
Діагностичний процес $\left(\mathrm{D}^{\mathrm{q}}\right)$ являє собою послідовність дій медичного працівника з визначення значень ознак, що характеризують реальний об'єкт $p, 3$ метою підтвердження діагностичної гіпотези.

На вході в ДП, відповідно до обраної діагностичної гіпотези $\Psi_{i_{s}}$ припускається, що весь набір значень $\left\{\alpha^{i n}{ }_{i_{s}}\right\}$ ознак $\left\{\gamma^{i n}{ }_{i_{s}}\right\}$, які характеризують реальний об'єкт $p_{i}^{\text {in }}$ на вході в ДП, попадає в інтервали $\left[a^{i n}, b_{i}{ }_{i}\right]$, котрі характеризують простір ознак стандартного (для даної гіпотези) об'єкта $\widetilde{p}^{i n}{ }_{i}$, тобто $p^{i n}{ }_{i}$ $=\tilde{p}^{i n}{ }_{i}=\left\{\tilde{\gamma}_{i_{1}}^{i n}, \tilde{\gamma}_{i_{2}}^{i n}, \ldots, \tilde{\gamma}_{i_{k}}^{i n}\right\}$. Звідсиval: $\left\{\gamma_{i_{s}}^{i n}\right\}$ $\rightarrow\left\{\alpha^{i n}{ }_{i_{s}}\right\}$ таке, що $\operatorname{val}\left(\gamma^{i n}{ }_{i_{s}}\right)=\alpha^{i n}{ }_{i_{s}} \in\left[a^{i n}, b^{i n}{ }_{i}\right]$. Тобто припускається, що $W\left(p^{i n}\right)=W\left(\tilde{p}_{i}{ }_{i}\right) \in \Psi_{i_{s}}$.

Власне реальний діагностичний процес складається 3 набору послідовних стандартних дій лікаря щодо встановлення значень тих ознак, що характеризують патологічний процес і відповідає обраній діагностичній гіпотезі. Отже, при роботі з реальним об'єктом значення ознак, що обрані для дослідження згідно діагностичної гіпотези (ДГ), спочатку не визначені: $\operatorname{val}\left(\gamma_{i_{s}}^{i n}\right) \in \varnothing$, а по завершенні ДП визначається точне значення ознаки та перевіряється іï належність інтервалам стандартного хворого $\operatorname{val}\left(\gamma_{i_{s}}^{\text {in }}\right)=\alpha^{i n}{ }_{i_{s}} \in\left[a^{i n}{ }_{i}, b^{i n}{ }_{i}\right]$.

Тобто модель ДП являє собою опис деяких стандартних дій, за допомогою яких можуть бути встановлені значення ознак стандартного хворого [3].

Діагностичний процес $\left(D_{i}^{q}\right)$ під час телемедичної консультації являє собою послідовність дій лікаря із визначення значень $\left\{\alpha^{i n}{ }_{i_{s}}\right\}$ ознак $\left\{\gamma^{i n}{ }_{i_{s}}\right\}$, що харак- 
теризують пацієнта $p_{i}, 3$ метою підтвердження діагностичної гіпотези $\Psi_{i_{s}}$, де $i=\overline{1, q}, s=\overline{l, k}$.

Згідно з визначенням діагностичної гіпотези, їі основним елементом є стандартний хворий, який може бути описаний як фіксована множина інтервалів\{ $\left[a_{i_{1}}\right.$, $\left.\left.b_{i_{1}}\right],\left[a_{i_{2}}, b_{i_{2}}\right], \ldots,\left[a_{i_{k}}, b_{i_{k}}\right]\right\}$, в які повинні потрапля- ти значення $\left\{\widetilde{\alpha}_{i_{1}}, \widetilde{\alpha}_{i_{2}}, \ldots, \widetilde{\alpha}_{i_{k}}\right\}$ ознак $\left\{\widetilde{\gamma}_{i_{1}}, \widetilde{\gamma}_{i_{2}}\right.$ $\left.\widetilde{\gamma}_{i_{k}}\right\}$ стандартного об'єкта $\tilde{p}_{i}$ при вимірюванні.

Весь діагностичний процес можна представити як набір діагностичних досліджень, результати яких використовуються в процесі підтвердження діагностичної гіпотези (рис. 2).

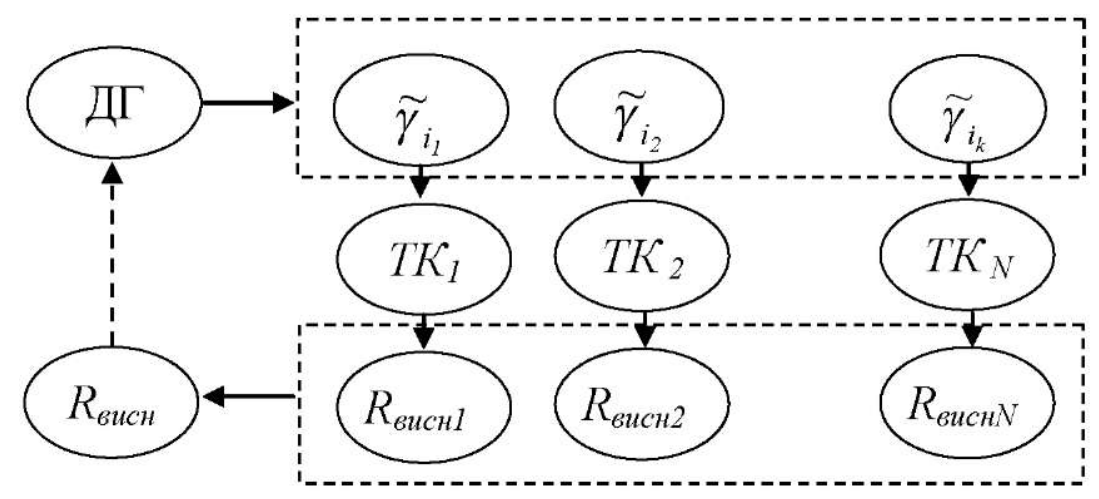

Puc. 2. Схема діагностичного процесу.

Для визначення основних складових процесу діагностичних досліджень необхідно провести його аналіз.

На значення ознаки, що виходить при вимірюванні, прямо впливає та складова об'єкта вимірювання, що він описує. Залежно від місця вимірювання дана ознака набуває різних значень при тому ж самому стані пацієнта.

Отже, ознака, що характеризує об'єкт, має ще й обов'язковий атрибут - місце вимірювання $\left(a_{3}\right)$ Як одне джерело одержання даних може бути описано цілим набором ознак, так і конкретна ознака може належати різним джерелам. Тому тільки явно описана пара: "джерело даних" - "ознака", дає можливість у результаті вимірювання визначити значення ознаки.

У свою чергу, технологія вимірювання (або метод одержання інформації), є тим компонентом, що також впливає на значення ознаки. Тобто, використовуючи різні методи вимірювання ознаки, можна одержати іiі різні значення. Схема послідовності дій представлена на рисунку 3 .

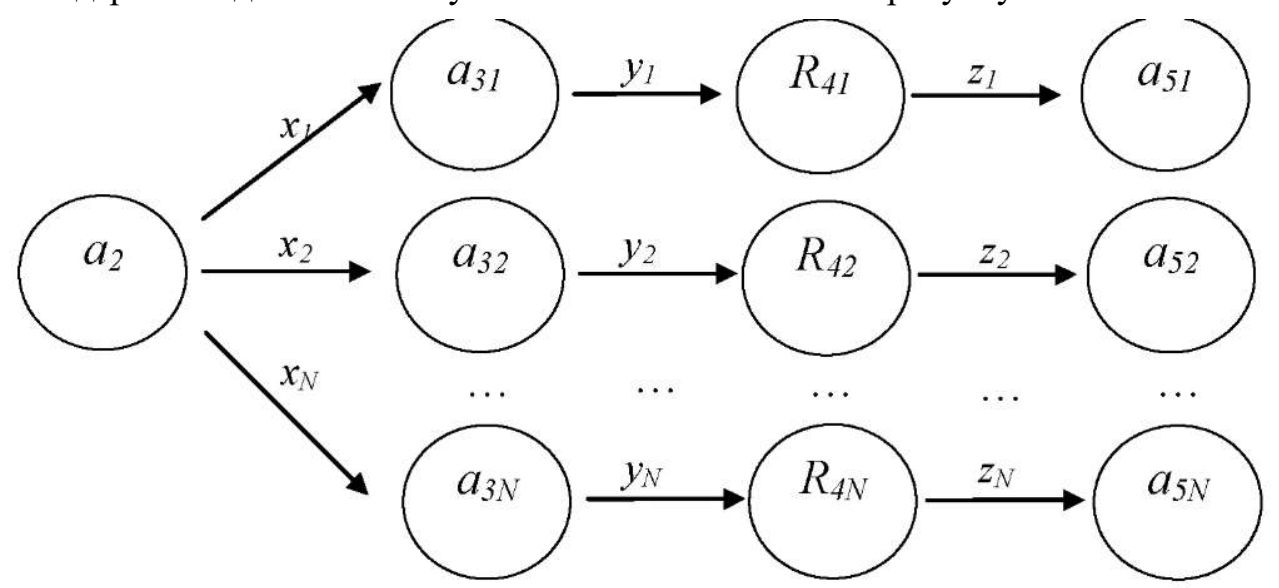

Puc. 3. Схема діагностичного процесу при ТК.

Станами автомату $є$ :

$A=\left\{a_{2}, a_{31}, a_{32}, \ldots, a_{3 N} R_{41}, R_{42}, \ldots, R_{4 N}, a_{51}, a_{52}\right.$ $\left.\ldots, a_{5 N}\right\}$.

$X=\left\{x_{1}, x_{2}, \ldots, x_{N}, y_{1}, y_{2}, \ldots, y_{N}, z_{1}, z_{2}, \ldots, z_{N}\right\}-$ входить алфавіт.

$$
\left.\begin{array}{l}
f\left(a_{2}, x_{s}\right)=a_{3 s} \\
f\left(a_{3 s}, y_{s}\right)=R_{4 s} \\
f\left(R_{4 s}, z\right)=a_{5 s}
\end{array}\right\}
$$

функції переходів (часткові). 
Самі результати вимірювання, як правило, не дають тієї характеристики об'єкта, що допомагає прийняти кінцеве лікарське рішення. Необхідно задіяти процес аналізу й інтерпретації отриманих даних.

Наступним компонентом у прийнятті рішень $є$ процес аналізу отриманих даних $\left(\mathrm{R}_{6}\right)$. При цьому для одного набору даних можуть існувати різні методи їхнього аналізу. Наприклад, якщо клінічна лабораторія змінює діапазони норм, то висновки, отримані при аналізі результатів вимірювання, також можуть змінюватися.

Саме вид інформації, що отримується в результаті аналізу $\left(a_{7}\right)$, визначається методом аналізу.

Останнім компонентом діагностичного "ланцюга" $\epsilon$ процедура висновку $\left(R_{8}\right)$. При цій процедурі лікар:

1) аналізує отримані в результаті вимірювання дані;

2) визначає, чи дійсно досягнута мета, що ставилася на вході в діагностичний "ланцюг";

3) визначає валідність отриманих даних;

4) робить висновок, що надалі буде брати участь у встановленні діагнозу.

Отже, весь діагностичний ланцюг з визначення висновку, щодо стану досліджуваної ознаки включає такі складові: $a_{2}$ - ознака, що вимірюється;

$a_{3}$ - джерело, 3 якого витягається інформація;

$R_{4}$ - метод отримання інформації;

$a_{5}$ - вид отриманої інформації;

$R_{6}$ - метод аналізу отриманої інформації;

$a_{7}$ - вид інформації, що отримана в результаті аналізу;

\section{$R_{8}$}

$a_{9}$ - результати висновку й оформлення в документації стадій ДП.

Процедурними концептами процесу діагностичного вимірювання $\epsilon: R_{1}$ - визначення мети; $R_{4}$ - одержання інформації; $R_{6}$ - аналіз отриманої інформації; $\mathrm{R}_{8}$ - висновок (співвіднесення з метою) і оформлення медичної документації.

Структурними концептами елементарного блоку діагностичного знання $є: a_{1}$ - ціль; $a_{2}$ - ознака, що вимірюється; $a_{3}$ - джерело, 3 якого одержується інформація; $a_{5}$ - вид отриманої інформації; $a_{7}$ - вид інформації, отриманої в результаті аналізу; $a_{9}$ - результати висновку (рис. 4).

Приклад використання процедурних і структурних концептів наведено у таблиці 1.

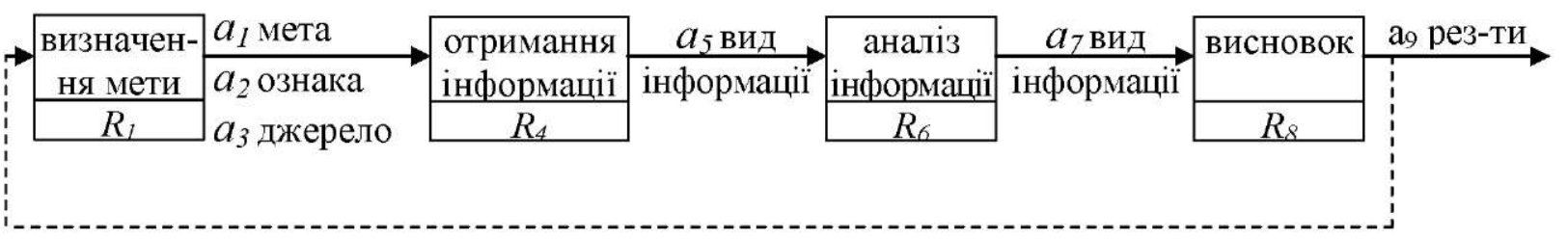

Puc. 4. Концепти елементарного блоку діагностичного знання.

Таблиця 1. Приклад використання процедурних і структурних концептів

\begin{tabular}{|c|l|l|}
\hline Індекс & \multicolumn{1}{|c|}{ Найменування концепту } & \multicolumn{1}{|c|}{ Приклад } \\
\hline$a_{1}$ & $\begin{array}{l}\text { мета, 3 якою здійснюється діагностичний } \\
\text { вплив }\end{array}$ & початок дослідження \\
\hline$a_{2}$ & ознака, що вимірюється & тривалість і частота \\
\hline$a_{3}$ & джерело, з якого отримується інформація & орган, що досліджується \\
\hline$R_{4}$ & метод отримання інформації & клінічний метод \\
\hline$a_{5}$ & вид отриманої інформації & тривалість, частота \\
\hline$R_{6}$ & метод аналізу отриманої інформації & розрахунок за таблицями \\
\hline$a_{7}$ & вид інформації, отриманої в результаті аналізу & тип діяльності (слабка, задовільна, активна) \\
\hline$R_{8}$ & висновок (співвідношення з метою) & підтвердження попереднього висновку \\
\hline$a_{9}$ & оформлення в документації стадій дП & індивідуальна карта пацієнта \\
\hline
\end{tabular}

Для детального аналізу руху інформації в процесі діагностичного обстеження під час телемедичного консультування (ТК) можна представити за допомогою методології структурного аналізу та проектування SADT (Structure Analysis \& Design Technique) IDEF 0 [2].

Відображення процесу ТК наведено на рисунку 5.
Висновок $\left(a_{9}\right)$, що повинен зробити лікар за результатами вимірювання ознаки, залежить від цілого ряду змін факторів, що є складовими діагностичного процесу. Змінні фактори являють собою такі набори взаємин і обмежень (даний опис має приблизну онтологічну картину):

1) набір джерел $\left(a_{3}\right)$, $з$ яких одержується інформація, обмежується вимірюваною ознакою $\left(a_{2}\right)$; 


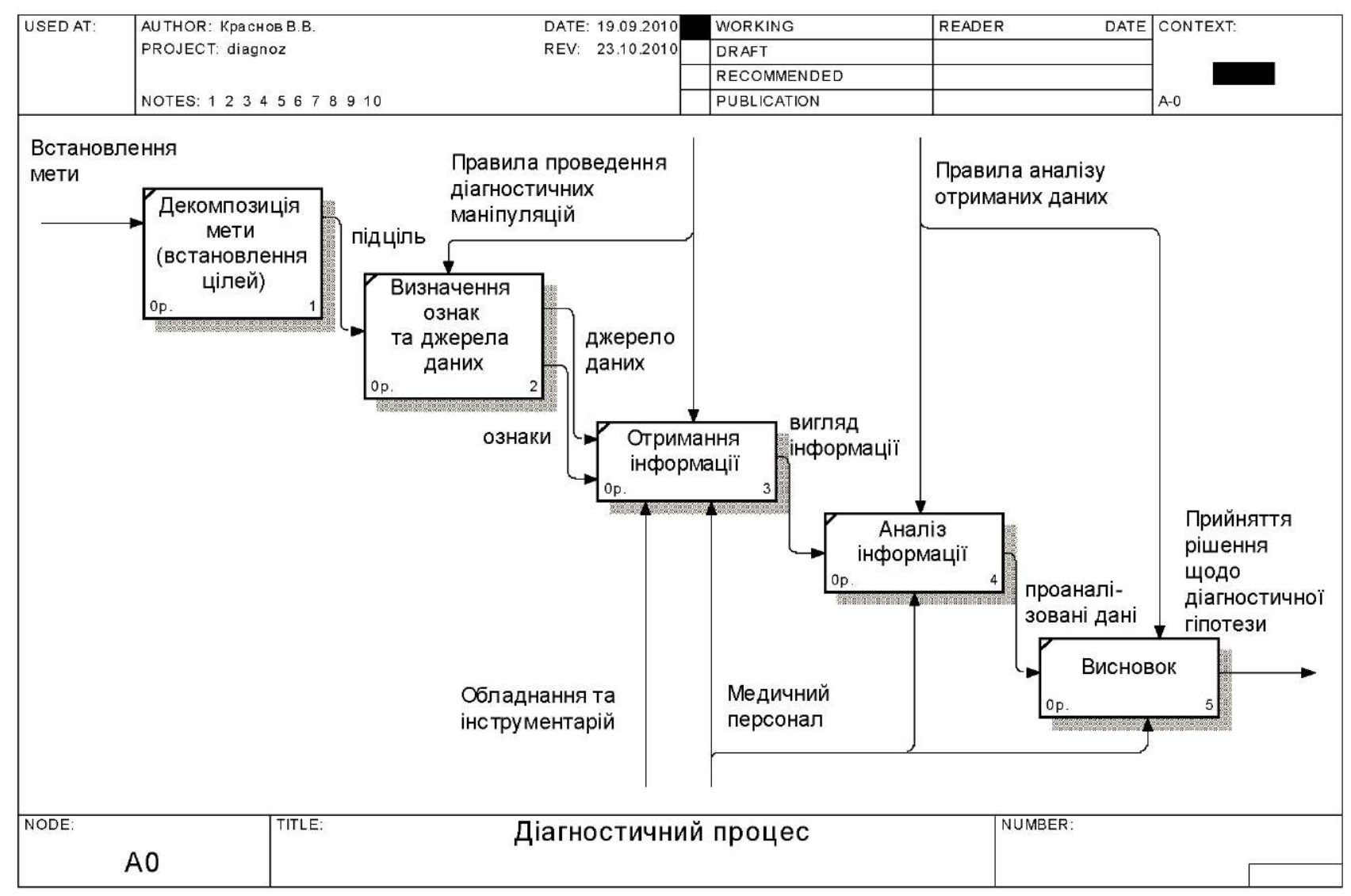

Puc. 5. Представлення ДП під час телемедичного консультування в форматі процесного підходу.

2) набір методів одержання інформації $\left(R_{4}\right)$ обмежується вимірюваною ознакою $\left(a_{2}\right)$ і джерелом одержання інформації $\left(a_{3}\right)$;

3) вид отриманої інформації $\left(a_{5}\right)$, обмежується методом одержання інформації $\left(a_{4}\right)$;

$4)$ метод аналізу отриманої інформації $\left(R_{6}\right)$, обмежується методом одержання інформації $\left(a_{4}\right)$;

5) вид інформації, отриманої в результаті аналізу $\left(a_{7}\right)$, обмежується методом аналізу отриманої інформації $\left(a_{6}\right)$;

6) процес висновку $R_{8}$ і результати висновку $a_{9}$ залежать від всіх попередніх складових.

Весь набір перерахованих складових перебуває під впливом головного фактора - мети $\left(a_{1}\right)$, що визначає (або обмежує) очікуваний висновок і пов'язані з ним набори елементів процесу ДП.

Введемо поняття формалізованого опису лікувального прочесу під час телемедичної консультаціï. Вище воно частково було розглянуто. Будемо розуміти під лікувальним процесом $\left(L_{i}^{q}\right)$ - послідовність стандартизованих лікувальних впливів, що здійснюються 3 метою переводу пацієнта зі стану, що відповідає стану стандартного пацієнта на вході в КП (тобто $W\left(p^{i n}\right)=W\left(\tilde{p}^{i n}{ }_{i}\right)$, де $p_{i}^{i n}=\left\{\tilde{\gamma}_{i_{1}}{ }^{i n}, \tilde{\gamma}^{i n}{ }_{i_{2}}\right.$, $\left.\ldots, \tilde{\gamma}^{i n}{ }_{i_{k}}\right\}$ i $\operatorname{val}\left(\gamma_{i_{s}}^{i n}\right)=\alpha^{i n}{ }_{i_{s}} \in\left[a_{i}^{i n}, b^{i n}{ }_{i}\right]$, у стан, що також відповідає стану стандартного об' єкта на виході з КП (тобто $W\left(p^{\text {out }}\right)=W\left(\tilde{p}^{\text {out }}{ }_{i}\right)$, де $p^{\text {out }}{ }_{i}=$ $\left\{\tilde{\gamma}^{\text {out }}{ }_{i_{1}}, \tilde{\gamma}^{\text {out }}{ }_{i_{2}}, \ldots, \tilde{\gamma}^{\text {out }}{ }_{i_{k}}\right\} \mathrm{i} \operatorname{val}\left(\gamma^{\text {out }}{ }_{i_{s}}\right)=\alpha^{\text {out }}{ }_{i_{s}} \in$ $\left.\left[a^{\text {out }}{ }_{i}, b^{\text {out }}{ }_{i}\right]\right)$.

При невідповідності параметрів стану пацієнта заданим критеріям стан об'єкта вважається вже таким, що не належить простору ознак $W\left(\widetilde{p}^{\text {out }}{ }_{i}\right)$ і об'єкт повертається на початковий рівень діагностичного процесу (рис. 6). При цьому процедурними складовими моделі будемо вважати: мету; умови збігу реальної ситуації й ситуації-еталона (тотожність характеристик, тотожність цілей); умови початку дії (ознаки специфічної, пускової ситуації); правила декомпозиції мети (відображення послідовного набору дій на більш високому рівні подання, можна описувати як набори результатів (цілей) на "вході-виході" систем більш низьких рівнів); правила побудови взаємодії між цілями; правила побудови моделі реалізації мети; оцінювання ступеня досягнення очікуваного результату діяльності (контроль досягнення мети, "зворотний зв'язок"); умови припинення виконання дії. 


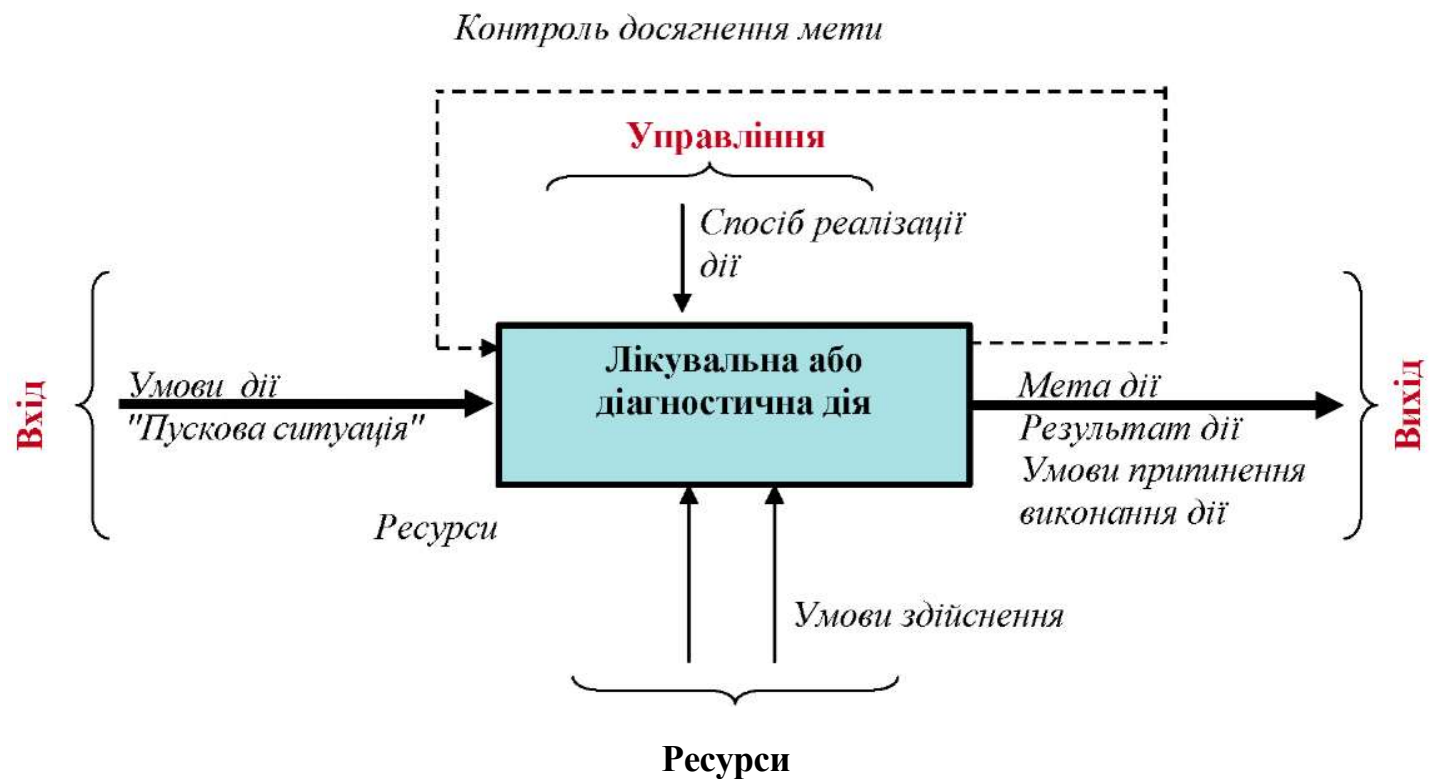

Puc. 6. Структурна модель умов проведення телемедичної консультації.

Висновки. 1. Специфіка телемедичних консультацій полягає в тому, що лікар-експерт, на відміну від лікаря-виконавця, при традиційних підходах використовує для прийняття рішень неповну або викривлену інформацію.

2. Усунення недоліків при телемедичному консуль-

\section{Література.}

1. Карпов Ю. Г. Теория автоматов / Ю. Г. Карпов. - СПб. : Питер, 2003. - 208 c.

2. Дэвид А. Марка SADT ${ }^{\mathrm{TM}}$. Методология структурного анализа и проектирования / Дэвид А. Марка, Клемент Л. туванні можливе шляхом введення уніфікованих стандартних правил організації медичних дій.

3. Моделювання, формалізація та подальша стандартизація лікарських маніпуляцій при ТК дозволить, з одного боку, мінімізувати помилки лікарів, з іншого боку - забезпечити наступність медичних дій.

МакГоуэн. - М. : МетаТехнология, 1993. - 240 с.

3. Попов Э. В. Корпоративные системы управления знаниями / Э. В. Попов // Новости искусственного интеллекта. 2001. - № 6. - С. 14-25. 